Aim of the study: Assessment of lung cancer patients' dietary habits before treatment enable medical staff to provide more individual, precise and complex care to patients, taking into consideration their nutritional status. The aim of this study was, therefore, to evaluate dietary habits related to lung cancer risk of lung cancer patients in comparison with controls from the Lower Silesia region of Poland.

Material and methods: Assessments of dietary habits, based on a validated questionnaire related to lung cancer risk were performed on 92 lung cancer patients and compared with the results obtained in 157 controls. Dietary patterns were evaluated concerning on eating frequency of high- and lowglycemic index products, vegetables and fruits, vegetable and fruit juices, green tea, liquid dairy products, meat and fried products over the previous year. Alcohol consumption was assessed on a dichotomous scale (yes or no).

Results: Majority of patients had inappropriate dietary habits, such as low consumption of low Gl cereal products, vegetables, fruit and green tea, and a high consumption frequency of fried products.

Conclusions: Reported dietary mistakes indicate the need for dietary education among people at lung cancer risk and with newly diagnosed disease, to enhance their nutritional status.

Key words: lung cancer, dietary habits, vegetable, fruits.

Contemp Oncol (Pozn) 2015; 19 (5): 391-395 DOI: $10.5114 /$ wo.2015.54084

\section{Dietary habits of lung cancer patients from the Lower Silesia region of Poland}

\author{
Katarzyna Zabłocka-Słowińska1, Irena Porębska², Marcin Gołecki², \\ Anna Prescha ${ }^{1}$, Joanna Pieczyńska ${ }^{1}$, Monika Kosacka ${ }^{2}$, Rafał llow ${ }^{1}$, \\ Halina Grajeta ${ }^{1}$, Renata Jankowska ${ }^{2}$, Jadwiga Biernat ${ }^{3}$
}

${ }^{1}$ Department of Food Science and Dietetics, Wroclaw Medical University, Wroclaw, Poland

2Department and Clinic of Pulmonology and Lung Cancers, Wroclaw Medical University, Wroclaw, Poland

${ }^{3}$ Department of Human Nutrition, Wroclaw University of Environmental and Life Sciences, Wroclaw, Poland

\section{Introduction}

The main risk factor for lung cancer is cigarette smoking. However, nutrition may influence the development and progression of this cancer to a certain extent. High consumption of vegetables, fruit and green tea may protect against lung cancer development, while consumption of meat and fried products increases the risk of this disease [1-4]. Deterioration of dietary habits occurs very often in the elderly and results from social, economic and health problems. Even with a high standard of living, the elderly often consume a characteristically monotonous diet, and fall into malnutrition due to food intake difficulty $[5,6]$. Lung cancer morbidity is highest in the sixth and seventh decades of life; thus age-related quality deterioration in the diet may accelerate the occurrence and progression of the illness [7].

The aim of this study was to evaluate selected dietary habits related to lung cancer risk in lung cancer patients and compare them with healthy subjects from the Lower Silesia region of Poland.

\section{Material and methods}

Ninety-two subjects, 23 female (56.4 \pm 9.4 year) and 69 male (65.5 \pm 8.6 year), with newly diagnosed lung cancer were recruited to this study from the Lower Silesian Centre of Lung Diseases. $72.8 \%$ of the patients had nonsmall cell lung cancer (NSCLC), 16.3\% had small-cell lung cancer, and for the rest of the group data about histologic type were not collected. The control group consisted of 157 healthy inhabitants of Lower Silesia, 47 female (55.7 \pm 15.6 year) and 110 male $(63.1 \pm 13.7$ year), recruited from senior clubs and an occupational medical center. Subjects suffering from cancers, metabolic and mental diseases and/or under dietary treatment were excluded. Control and lung cancer groups were sex- and age-matched. The baseline sociodemographic status of lung cancer and control subjects is presented in Table 1. Patients were less educated than controls. Almost $1 / 3$ of patients and only $6 \%$ of controls had only graduated from primary school. Marital status also significantly differentiated patients and controls - a higher percentage of patients were married. Almost $69 \%$ of patients and $36 \%$ of controls had formerly smoked, and every fourth patient and control was a current smoker.

Dietary interviews were carried out during the first day of the patients' admission and were also performed on control subjects by trained dieticians. Dietary habits related to lung cancer risk were assessed using a validated questionnaire [8] based on the consumption frequency of low- and high-glycemic-index (Gl) carbohydrate products, vegetables and fruits, veg- 
Table 1. Selected elements of sociodemographic status of lung cancer patients $(n=92)$ and control subjects $(n=157)$

\begin{tabular}{|c|c|c|c|c|c|}
\hline \multirow[t]{2}{*}{ Characteristics } & \multicolumn{2}{|c|}{ Patients } & \multicolumn{2}{|c|}{ Control subjects } & \multirow[t]{2}{*}{$p$} \\
\hline & Female & Male & Female & Male & \\
\hline Age [mean \pm SD] & $56.4 \pm 9.4$ & $65.5 \pm 8.6$ & $55.7 \pm 15.6$ & $63.1 \pm 13.7$ & \\
\hline \multicolumn{6}{|c|}{ Level of education, $n$ ( $\%$ of all patients and controls) } \\
\hline Primary school & \multicolumn{2}{|c|}{$26(28.3)$} & \multicolumn{2}{|c|}{$10(6.4)$} & $<0.01$ \\
\hline Secondary school, lower level & \multicolumn{2}{|c|}{$37(40.2)$} & \multicolumn{2}{|c|}{$55(35.0)$} & \\
\hline Secondary school, higher level & \multicolumn{2}{|c|}{$19(20.7)$} & \multicolumn{2}{|c|}{$55(35.0)$} & \\
\hline Postsecondary & \multicolumn{2}{|c|}{$10(10.9)$} & \multicolumn{2}{|c|}{$37(23.6)$} & \\
\hline \multicolumn{6}{|c|}{ Marital status, $n$ ( $\%$ of all patients and controls) } \\
\hline Single & \multicolumn{2}{|c|}{$6(6.5)$} & \multicolumn{2}{|c|}{$24(15.3)$} & 0.02 \\
\hline Married & \multicolumn{2}{|c|}{$74(80.4)$} & \multicolumn{2}{|c|}{$101(64.3)$} & \\
\hline Divorced/Widower & \multicolumn{2}{|c|}{$12(13.0)$} & \multicolumn{2}{|c|}{$32(20.4)$} & \\
\hline \multicolumn{6}{|c|}{ Cigarette smoking $n$ ( $\%$ of all patients and controls) } \\
\hline Current smokers & \multicolumn{2}{|c|}{$23(25.0)$} & \multicolumn{2}{|c|}{$40(25.5)$} & $<0.01$ \\
\hline Former smokers & \multicolumn{2}{|c|}{$63(68.5)$} & \multicolumn{2}{|c|}{$57(36.3)$} & \\
\hline Never smokers & \multicolumn{2}{|c|}{$6(6.5)$} & \multicolumn{2}{|c|}{$60(38.2)$} & \\
\hline \multicolumn{6}{|c|}{ No. of cigarettes, $n$ (\% of patients and controls who smoked) } \\
\hline$<5 /$ day & \multicolumn{2}{|c|}{$4(17.4)$} & \multicolumn{2}{|c|}{$5(12.5)$} & NS \\
\hline $5-20 /$ day & \multicolumn{2}{|c|}{$11(47.8)$} & \multicolumn{2}{|c|}{$28(70.0)$} & \\
\hline$>$ 20/day & \multicolumn{2}{|c|}{$8(34.8)$} & \multicolumn{2}{|c|}{$7(17.5)$} & \\
\hline
\end{tabular}

etable and fruit juices, green tea, milk and liquid dairy products, meat, fried products and alcohol. Dietary patterns were evaluated concerning the eating frequency of these food products over the previous year. Alcohol consumption was assessed on a dichotomous scale (yes or no). The answer "no" means that the subject did not drink alcohol or drank it very occasionally (less than one drink/ beer/glass of wine per month). The data were analyzed using Statistica 10 (StatSoft). The distribution of dietary habits among patients and controls were compared using the $\chi^{2}$ test. The study was reviewed by the local ethics committee and was performed in accordance with the Declaration of Helsinki.

\section{Results}

The comparison of dietary habits related to lung cancer risk for patients and controls is presented in Table 2. Both patients and controls preferred high-glycemic-index (GI) cereal products. More than half the patients and ca. $43 \%$ of controls consumed these products three or more times per day. This frequency of low Gl cereal product consumption was not shown in patients and occurred in only ca. $6 \%$ of controls $(p<0.01)$. Moreover, the majority of patients ate low GI cereal products irregularly.

Patients and controls ate vegetables with a similar frequency. Most of them consumed 2-3 portions of vegetables a day (43.5\% of patients, $47.8 \%$ of controls) or 1 portion a day ( $45.6 \%$ of patients, $42.0 \%$ of controls). The frequency of fruit consumption was generally low: $43.5 \%$ of patients and $26.8 \%$ of controls ate fruits irregularly. Apart from fruit and vegetable intake assessment, the frequency of vegetable and fruit juice consumption was also evaluated, but there were no significant differences in the drinking of these products. The majority of patients (75.0\%) and controls (82.1\%) consumed less than 1 glass of vegetable juice per week. Half of the patients and about $44 \%$ of controls drank fruit juices with this frequency.

Lung cancer patients and the control group drank green tea with a low frequency, and there were no statistically significant differences between groups. The consumption of milk and liquid dairy products by patients and controls was generally insufficient. The highest percentage of patients (52.2\%) and controls (46.5\%) drank these products irregularly. Patients ate meat with significantly lower frequency than controls $(p<0.01)$. About one-third of patients and one-fourth of controls ate meat irregularly. It was also found that a statistically higher percentage of patients than controls ate fried products every day $(16.3 \%$ vs. $10.3 \%)(p=0.01)$

Alcohol consumption was also assessed statistically, and significantly larger proportion of lung cancer patients (52.2\%) than control subjects (23.6\%) had not drunk alcohol in the previous year $(p<0.01)$.

\section{Discussion}

High lung cancer morbidity and mortality are the main impulses for researching new possible ways of fighting this disease. The major risk factor is smoking, and in this study it was also found that the majority of patients were current $(25.0 \%)$ or former smokers (68.5\%). Additionally, low sociodemographic status expressed mainly by low educational level and household income positively correlates 
Table 2. Dietary habits of lung cancer patients $(n=92)$ and control subjects $(n=157)$

\begin{tabular}{|c|c|c|c|c|}
\hline Dietary habits & & $\begin{array}{l}\text { Lung cancer patients } \\
n(\%)\end{array}$ & $\begin{array}{c}\text { Control subjects } \\
n(\%)\end{array}$ & $P$ \\
\hline \multirow[t]{3}{*}{ High-GI cereal products } & $\geq 3$ portions a day & $51(55.4)$ & $68(43.3)$ & \multirow[t]{3}{*}{ NS } \\
\hline & 1-2 portions a day & $38(41.3)$ & $74(47.1)$ & \\
\hline & Irregularly & 3 & $15(9.6)$ & \\
\hline \multirow[t]{3}{*}{ Low-GI cereal products } & $\geq 3$ portions a day & $0(0.0)$ & $9(5.7)$ & \multirow[t]{3}{*}{$<0.01$} \\
\hline & 1-2 portions a day & $36(39.1)$ & $67(42.7)$ & \\
\hline & Irregularly & $56(60.9)$ & $81(51.6)$ & \\
\hline \multirow[t]{4}{*}{ Vegetables } & $\geq 4$ portions a day & $2(2.2)$ & $7(4.5)$ & \multirow[t]{4}{*}{ NS } \\
\hline & 2-3 portions a day & $40(43.5)$ & $75(47.8)$ & \\
\hline & 1 portion a day & $42(45.6)$ & $66(42.0)$ & \\
\hline & Irregularly & $8(8.7)$ & $9(5.7)$ & \\
\hline \multirow[t]{4}{*}{ Fruit } & $\geq 4$ portions a day & $7(7.6)$ & $12(7.6)$ & \multirow[t]{4}{*}{ NS } \\
\hline & 2-3 portions a day & $20(21.7)$ & $44(28.0)$ & \\
\hline & 1 portion a day & $25(21.2)$ & $59(37.6)$ & \\
\hline & Irregularly & $40(43.5)$ & $42(26.8)$ & \\
\hline \multirow[t]{4}{*}{ Vegetable juices } & $\geq 1$ glass a day & $5(5.4)$ & $3(1.9)$ & \multirow[t]{4}{*}{ NS } \\
\hline & 4-6 glasses a week & $4(4.4)$ & $3(1.9)$ & \\
\hline & 1-3 glasses a week & $14(15.2)$ & $22(14.1)$ & \\
\hline & < one glass a week & $69(75.0)$ & $128(82.1)$ & \\
\hline \multirow[t]{4}{*}{ Fruit juices } & $\geq 1$ glass a day & $22(23.9)$ & $22(14.1)$ & \multirow[t]{4}{*}{ NS } \\
\hline & 4-6 glasses a week & $3(3.3)$ & $10(6.4)$ & \\
\hline & 1-3 glasses a week & $21(22.8)$ & $55(35.3)$ & \\
\hline & < one glass a week & $46(50.0)$ & $69(44.2)$ & \\
\hline \multirow[t]{4}{*}{ Green tea } & $\geq 1$ glass a day & $8(8.7)$ & $32(20.5)$ & \multirow[t]{4}{*}{ NS } \\
\hline & 4-6 glasses a week & $2(2.2)$ & $2(1.3)$ & \\
\hline & 1-3 glasses a week & $7(7.6)$ & $15(9.6)$ & \\
\hline & < one glass a week & $75(81.5)$ & $107(68.6)$ & \\
\hline \multirow{4}{*}{$\begin{array}{l}\text { Milk and liquid dairy } \\
\text { products }\end{array}$} & $\geq 4$ glasses a day & $5(5.4)$ & $7(4.5)$ & \multirow[t]{4}{*}{ NS } \\
\hline & 2-3 glasses a day & $9(9.8)$ & $34(21.6)$ & \\
\hline & $0.5-1$ glass a day & $30(32.6)$ & $43(27.4)$ & \\
\hline & Irregularly & $48(52.2)$ & $73(46.5)$ & \\
\hline \multirow[t]{4}{*}{ Meat } & $\geq 4$ portions a day & $0(0.0)$ & $5(3.2)$ & \multirow[t]{4}{*}{$<0.01$} \\
\hline & 2-3 portions a day & $23(25.0)$ & $61(38.9)$ & \\
\hline & 1 portion a day & $37(40.2)$ & $55(35.0)$ & \\
\hline & Irregularly & $32(34.8)$ & $36(22.9)$ & \\
\hline \multirow[t]{4}{*}{ Fried products } & Every day & $15(16.3)$ & $16(10.3)$ & \multirow[t]{4}{*}{0.01} \\
\hline & 4-6 portions a week & $10(10.9)$ & $40(25.6)$ & \\
\hline & 1-3 portions a week & $60(65.2)$ & $82(52.6)$ & \\
\hline & $<1$ portion a week & $7(7.6)$ & $18(11.5)$ & \\
\hline \multirow[t]{2}{*}{ Alcohol consumption } & Yes & $44(47.8)$ & $120(76,4)$ & \multirow[t]{2}{*}{$<0.01$} \\
\hline & No & $48(52.2)$ & $37(23.6)$ & \\
\hline
\end{tabular}


with lung cancer risk $[9,10]$, which was also partially confirmed in this study. Diet may contribute to the development and progression of lung cancer. Studies concerning the lung cancer patient's dietary habits have not been carried out in Poland yet.

\section{Dietary habits}

A high $\mathrm{Gl}$ diet increases cancer risk due to increased blood glucose concentration, insulin ejection and insulin growth factor (IGF) activity [11]. In this study it was found that patients consumed low Gl products with lower frequency than control subjects, although George et al. [11] did not find a correlation between the type of Gl of products consumed and lung cancer risk in a prospective study. In the aforementioned study an assessment of the influence of GI on cancer risk was performed with a 124-item food frequency questionnaire, and we focused only on cereal products, which may be the reason for the inconsistency in results.

The protective effect of vegetables and fruit against lung cancer development has been well demonstrated, although it was dependent on the type of group studied and the type of research. Smith-Warner et al. [12] found that high fruit and vegetable consumption modestly reduced lung cancer risk, and the influence was mainly attributed to fruit. Linseisen et al. [13] demonstrated a protective role only for fruit. In this study vegetable consumption also decreased lung cancer risk, but only in current smokers, in contrast to the observations of Jansen et al. [14], where vegetable consumption was not related to lung cancer risk in smokers.

In this study, vegetable and fruit consumption was relatively low. Juices were even more rarely drunk and did not enhance the intake of valuable components of vegetables and fruit. The low consumption of these food groups could be, additionally to cigarette smoking, a risk factor for lung cancer development. Therefore dietary education is indicated to promote a higher frequency of vegetable and fruit consumption. As previously stated [15], a high frequency of fruit and vegetable consumption may bring benefits for cancer patients, e.g. an improvement in quality of life. Increased consumption of green tea protects against carcinogenesis [16]. Zhong et al. [17] found that consumption of green tea decreased lung cancer risk among women. The effect was stronger in the non-smoking-group [17]. Laurie et al. [18] determined the anticancer activity of green tea extract against advanced lung cancer. About $40 \%$ of recruited patients had a stable disease ranging from 4 to 16 weeks. The authors suggest that green tea extract could be used as a chemo-preventive or chemotherapy-enhancing factor. Sadava et al. [19] found that epigallocatechin-3-gallate occurring in green tea decreased telomerase, caspase- 3 and caspase- 9 activity, but not caspase-8, which indicated apoptosis induction. Zhang et al. [20] also found that green tea extract exhibits protective activity against lung cancer and decreased benzo-á-pyrene-dihydrodiol-epoxide (BPDE)-induced DNA damage in lymphoid cells from lung cancer patients.
We observed a very low frequency of green tea consumption among all subjects, with no statistically significant difference between patients and controls. Green tea contains potential cancer-fighting compounds [21] and therefore may be recommended as a healthy beverage among lung cancer patients, as well as healthy subjects, especially those who smoke cigarettes.

Dairy products are a source of biologically active compounds, e.g. calcium, vitamin D and conjugated linoleic acid, which possesses a broad spectrum of anticarcinogenic activity [21]. Takezaki et al. [22] found that frequency of milk consumption correlated negatively with squamous cell lung carcinoma and small cell lung cancer occurrence in the male group. In contrast to this observation, De Stefani et al. [23] observed no correlation between the frequency of milk consumption and lung cancer morbidity. In this study the highest percentage of patients consumed milk and liquid dairy products irregularly and did not differ in this respect from the controls. A low consumption of dairy products might influence disease development and contribute to nutritional status deterioration in patients, as dairy products provide easily digested protein.

Increased meat consumption may correlate positively with several type of cancers including lung cancer [24]. De Stefani et al. [25] found a correlation of total meat consumption with some histologic types of lung cancer: squamous cell carcinoma, adenocarcinoma and large cell carcinoma. In our study patients ate meat with a statistically lower frequency than controls, which indicates that this was not a significant risk factor for the development of the disease. However, the low consumption of this rich source of valuable protein and iron may increase malnutrition and anemia risk - paraneoplastic symptoms often correspond to lung cancer.

Fried food products can cause cancerogenesis [26-28]. For example, acrylamide, occurring e.g. in fried potatoes, led to lung cancer development in an animal study [26]. Some other studies indicate that fried meat can increase lung cancer risk [27, 28]. Sinha et al. [28] found that heterocyclic amine-2-amino-3,4,8-trimethylimidazo[4,5-f]quinoxaline (MelQx) was associated with lung cancerogenesis.

In this study patients ate fried products with a higher frequency than controls, which might influence disease development and is generally inappropriate not only in the prevention of different kind of cancers but also in a well-balanced, healthy diet.

The influence of alcohol consumption on lung cancer risk is ambiguous. Freudehein et al. [29] found that drinking alcohol was slightly associated with lung cancer risk. The risk was stronger among never smoked male subjects. On the other hand, in the study by Bagnardi et al. [30], alcohol consumption was found to be a risk factor for lung cancer but only in smokers. This author with co-workers [31] performed a meta-analysis concerning alcohol consumption and risk of lung cancer in never smokers. They found that alcohol does not independently affect the risk of lung cancer. In our study a significantly lower percentage of lung cancer patients drank alcohol during the previous year than control subjects, which could have resulted from disease development and their worse health condition. 
Several limitations need to be acknowledged in this study. Since the healthy people were recruited from selected places (senior clubs and an occupational medical center), the control group might not be representative of the healthy population or, moreover, accurately comparable to the lung cancer patients. Moreover, lung cancer patients differed from the control group in educational level, smoking habits and marital status, which could have an impact on dietary habits. Secondly, although the majority of recruited patients had NSCLC, the lung cancer group was not homogeneous for histologic type. As mentioned above, some dietary habits may influence lung cancer risk only in certain histologic types. Taking into account the restrictions discussed above, the results of this study should be interpreted with some caution, and further research, excluding these limitations, is needed.

To summarize, lung cancer patients from the Lower Silesia region had inappropriate dietary habits, such as insufficient frequency of low GI cereal products, vegetables, fruit and green tea consumption and a high consumption frequency of fried products. This might additionally influence their lung cancer risk. The reported dietary mistakes indicate the need for dietary education among people at lung cancer risk and with newly diagnosed disease, to enhance their nutritional status.

\section{The authors declare no conflict of interest.}

\section{References}

1. Axelsson G, Liljeqvist T, Andersson L, Bergman B, Rylander R. Dietary factors and lung cancer among men in West Sweden. Int J Epidemiol 1996; 25: 32-9.

2. Wang H, Bian S, Yang CS. Green tea polyphenol EGCG suppresses lung cancer cell growth through upregulating miR-210 expression caused by stabilizing HIF-1 $\alpha$. Carcinogenesis 2011; 32: 1881-9.

3. Lam TK, Cross AJ, Consonni D, et al. Intakes of red meat, processed meat, and meat mutagens increase lung cancer risk. Cancer Res 2009; 69: 932-9.

4. Tang N-P, Zhou B, Wang B, Yu R.-B, Ma J. Flavonoids intake and risk of lung cancer: a meta-analysis. Jpn J Clin Oncol 2009; 39: 352-9.

5. Johansonn L, Thelle DS, Solvoll K, Bjorneboe A, Drevon CA. Healthy dietary habits in relation to social determinants and lifestylefactors. Brit J Nutr 1999; 81: 211-20.

6. Marshall TA, Stumbo PJ, Warren JJ, Xie X-J. Inadequate nutrient intake are common and are associated with low diet variety in rural, community-dwelling elderly. J Nutr 2001; 131: 2192-219.

7. Szczuka I, Roszkowski-Sliż K. Rak płuca w Polsce w latach 1970 2004. Pneumol Alergol Pol 2008; 76: 1-28

8. Ilow R, Królicka O, Regulska-Ilow B, Pluta J. Walidacja metody wywiadu częstotliwościowo-ilościowego do oceny sposobu żywienia wrocławskich studentek. Bromat Chem Toksykol 2005; 38: 313-20.

9. Zabłocka K, Krawczyszyn M, Pieczyńska J, et al. Assessment of sociodemographic and nutritional status of lung cancer patients. Rocz Panstw Zakl Hig 2011; 62: 433-8.

10. Mao Y, Hu J, Ugnat A-M, Semenciw R, Fincham S. and the Canadian Cancer Registries Epidemiology Research Group. Socioeconomic status and lung cancer risk in Canada. Int J Epidemiol 2001; 30: 809-17.

11. George SM, Mayne ST, Leitzmann MF, et al. Dietary glycemic index, glycemic load and risk of cancer: a prospective cohort study. Am J Epidemiol 2009; 169: 462-72.

12. Smith-Warner SA, Spiegelman D, Shiaw-Shyuan Y, et al. Fruits, vegetables and lung cancer: a pooled analysis of kohort studies. Int Cancer 2003; 107: 1001-11.
13. Linseisen J, Rohrmann S, Miller AB, et al. Fruit and vegetable consumption and lung cancer risk: updated information from the European Prospective Investigation into Cancer and Nutrition (EPIC). Int J Cancer 2007; 121: 1103-14.

14. Jansen MCJF, Bueno de-Mesquita HB, Räsänen L, Fidanza F, Nossonen AM, Menotti A, Kok FJ, Kromhout D. Kohort analysis of fruit and vegetable consumption and lung cancer mortality in European men. Int J Cancer 2001; 92: 913-8.

15. Blanchard CM, Courneya KS, Stein K. Cancer survivors' adherence to lifestyle behavior recommendations and associations with health-related quality of life: results from the American Cancer Society's SCS-II. J Clin Oncol 2008; 26: 2198-204.

16. Khan N, Mukhtar H. Cancer and metastasis: prevention and treatment by green tea. Cancer Meta Rev 2010; 29: 435-45.

17. Zhong L, Goldberg MS, Gao YT, Hanley JA, Parent M-E, Jin F. A population based case-control study of lung cancer and green tea consumption among women living in Shanghai, China. Epidemiol 2001; 12: 695-700.

18. Laurie SA, Miller VA, Grant SC, Kris MG, Ng KK. Phase I study of green tea extract in patients with advanced lung cancer. Cancer Chemother Pharmacol 2005; 55: 33-8.

19. Sadava D, Whitlock E, Kane SE. The green tea polyphenol, epigallocatechin-3-gallate inhibits telomerase and induces apoptosis in drug-resistant lung cancer cells. Biochem Biophys Res Commun 2007; 360: 233-7.

20. Zhang H, Spitz MR, Tomlinson GE, Schabath MB, Minna JD, Wu X. Modification of lung cancer susceptibility by green tea extracts as measured by comet assay. Cancer Detect Prevent 2002; 26: 411-8.

21. Adak M. Make a habit of green tea drinking for the prevention of cancer. Biochem Farmacol 2014; 3: 1-3.

22. Tsuda H, Sekine K. Milk components as cancer chemopreventive agents. Asian Pac J Cancer Prev 2000; 1: 277-82.

23. Takezaki T, Hirose K, Inoue M, Hamajima N, Yatabe Y, Mitsudomi T, Sugiera T, Kuroishi T, Tajima K. Dietary factors and lung cancer risk in Japanese: with special reference to fish consumption and adenocarcinomas. Brit J Cancer 2001; 84: 1199-206.

24. Bingham SA. High-meat diets and cancer risk. Proceed Nutr Soc 1999; 58: 243-8.

25. De Stefani E, Brennan P, Ronco A, Fierro L, Correa P, Boffetta P, Deneo-Pellegrini $\mathrm{H}$, Barrios $\mathrm{E}$. Food groups and risk of lung cancer in Uruguay. Lung Cancer 2002; 38: 1-7.

26. Rice JM. The carcinogenicity of acrylamide. Mutation Res 2005; 580: 3-20.

27. De Stefani E, Ronco AL, Boffetta P, Deneo-Pellegrini H, Acosta G, Mendilaharsu, M. Meat consumption, meat cooking, and risk of lung cancer among Uruguayan men. Asian Pac J Cancer Prev 2010; 11: 1713-7.

28. Sinha R, Kulldorff M, Swanson CA, Curtin J, Brownson RC, Alavanja MC. Dietary heterocyclic amines and the risk of lung cancer among Missouri women. Cancer Res 2000; 60: 3753-6.

29. Freudenheim JL, Ritz J, Smith-Warner SA, et al. Alcohol consumption and risk of lung cancer: a pooled analysis of cohort studies. Am J Clin Nutr 2005; 82: 657-67.

30. Bagnardi V, Randi G, Lubin J, et al. Alcohol consumption and lung cancer risk in the environment and genetics in lung cancer etiology (EAGLE) study. Am J Epidemiol 2009; 171: 36-44.

31. Bagnardi V, Rota M, Botteri E, et al. Alcohol consumption and lung cancer risk in never smokers: a meta-analysis. Ann Oncol 2011; 22: 2631-9.

\section{Address for correspondence}

\section{Katarzyna Zabłocka-Słowińska}

Department of Food Science and Dietetics

Wroclaw Medical University

Borowska 211

50-556 Wroclaw, Poland

e-mail: katarzynazablocka0112@gmail.com

Sumitted: $\quad 1.12 .2014$

Accepted: 15.12 .2014 